ISSN: 0212-0267

DOI: https://doi.org/IO.I420I/hedu202I40347368

\title{
EDUCAR COMO ACTO POLÍTICO: DE VUELTA A LA COMUNIDAD
}

\section{Educate as a political act: back to the community}

\author{
Pedro Perera Méndez \\ Universidad de La Laguna \\ Correo-e: ppereram@ull.edu.es \\ Andrés GonzÁlez NovoA \\ Universidad de La Laguna \\ Correo-e: agonzaln@ull.edu.es
}

Recepción: 28 de junio de 2020. Envío a informantes: 13 de julio de 2020.

Aceptación definitiva: 20 de noviembre de 2020

RESUMEN: La educación no es neutral. La educación entendida como un acto neutral se convierte en un procedimiento técnico, burocrático, se reduce a lo metodológico. La globalización y el neoliberalismo amplifican los presupuestos positivistas que instan a lo educativo a envasarse al vacío, asépticamente, esterilizadamente, como si de un medicamento se tratase. Pero la medicina no es el medicamento ni la educación, conocimientos y competencias. Es preciso reflexionar, en este caso, desde la pedagogía, para imaginar cómo podemos ir desde la inmunidad hacia la comunidad. La pedagogía conforma el hecho educativo como acto político, no como acto en sí, sino como posibilidad de un acto político entre lo posible y lo imposible, un acto político que nos ofrece poder, nos empodera. Un acto político que no depende de la intención de los sujetos, es anterior a ellos. Urge imaginar una pedagogía política que construya un lugar de responsabilidad para la acción.

Palabras Clave: pedagogía; política; educación; comunidad; ética.

ABSTRACT: Education is not neutral. Education understood as a neutral act becomes a technical, bureaucratic procedure, reduced to the methodological. Globalization and neoliberalism amplify the positivist premises that urge the installation of vacuum-packed, aseptic, sterilized education, as if it were a medicine. But medicine is not medicine, neither education is knowledge and skills. It is necessary to reflect, in this case, from pedagogy, to imagine how we can go from immunity to community. Pedagogy can shape education as a political act, not as an act in itself but as 
a possibility of a political act between the possible and the impossible, a political act that offers us power, that empowers us. A political act that does not depend on the intention of the subjects, is previous to them. It is urgent to imagine a political pedagogy that builds a place of responsibility for action.

KEY WORDS: pedagogy; politics; education; community; ethics.

\section{Revolviendo (a) la comunidad}

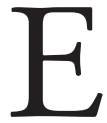

N LOS AÑOS SESENTA, Althusser (I988) sacudía al mundo académico denunciando a la escuela, junto con otras instituciones nacidas al calor de la modernidad burguesa, por ser uno de los aparatos ideológicos del Estado que mejor reproducía el statu quo. El sistema educativo fabricaba, decía Althusser, obreros, oficinistas, gerentes, intelectuales de la represión e intelectuales de la conducción capitalista. Todos nosotros ocuparíamos un lugar en el sistema, según el momento en que nos desgranáramos de él. Los hijos de obreros serían, por supuesto, los primeros en ser expulsados del sistema escolar, para ir rápidamente a las fábricas, y así sucesivamente, hasta ocupar los distintos lugares y jerarquías dentro de la sociedad capitalista. La escuela, según Althusser, nada podía hacer para modificar esto,

¿Qué se aprende en la escuela? Es posible llegar hasta un punto más o menos avanzado de los estudios, pero de todas maneras se aprende a leer, escribir y contar, o sea algunas técnicas, y también otras cosas, incluso elementos (que pueden ser rudimentarios o por el contrario profundizados) de «cultura científica» o «literaria» utilizables directamente en los distintos puestos de la producción (una instrucción para los obreros, una para los técnicos, una tercera para los ingenieros, otra para los cuadros superiores, etc.). Se aprenden «habilidades» (savor-faire).

Pero al mismo tiempo, y junto con esas técnicas y conocimientos, en la escuela se aprenden las «reglas» del buen uso, es decir de las conveniencias que debe observar todo agente de la división del trabajo, según el puesto que está «destinado» a ocupar: reglas de moral y de conciencia cívica y profesional, lo que significa en realidad reglas del respeto a la división social-técnica del trabajo y, en definitiva, reglas del orden establecido por la dominación de clase. Se aprende también a «hablar bien el idioma», a «redactar» bien, lo que de hecho significa (para los futuros capitalistas y sus servidores) saber «dar órdenes», es decir (solución ideal), «saber dirigirse» a los obreros, etcétera. (Althusser, 1988: 4)

Si la escuela, el sistema educativo, es un aparato ideológico de Estado es porque existe una enseñanza de un modelo sociopolítico determinado. Es porque se reproducen, en el tránsito educativo del sistema, unas relaciones que definen un tipo de sociedad'.

Estas relaciones son «las "relaciones de producción" de una formación social capitalista, es decir, las relaciones de explotados a explotadores y de explotadores a explotados» (AlthUSSER, 1988: 15). 
Tal como nos dice Paulo Freire, parece que olvidamos una verdad tan evidente como que todo acto educativo tiene naturaleza política ${ }^{2}$ (como todo acto político posee naturaleza educativa), está cargado de ideología, de valores. Por debajo de cualquier práctica educativa se halla un proyecto social del que podemos ser más o menos conscientes. Que la educación es siempre directiva y predicada sobre el supuesto de que la vida humana está más bien condicionada que determinada (Freire, 1970).

Y aun estando de acuerdo con la exposición del fundamento de la acción educativa, no se quisiera, desde estas líneas, dejar en manos de la praxis educativa la labor de crear las conciencias de resistencias. Se asume la opinión que, en una autocrítica a su propia labor de los primeros trabajos realizados, Henry Giroux nos comenta sobre el trabajo de estos dos autores,

[...] Lo que estas posiciones compartían era el paralizante supuesto de que las escuelas ni siquiera fueran lugares de conflicto, tampoco instituciones que pudieran ligar aprendizaje a cambio social. Dentro de esas perspectivas, los profesores y estudiantes pierden sus capacidades para ser agentes críticos, sirviendo, tanto el uno como el otro, como porteros ideológicos o como serviles lacayos del estado. Igualmente, la pedagogía fue, también, reducida a una colección estéril de técnicas o revestida dentro de un discurso de métodos humanistas que simplemente mitigaban los intentos, por parte de las escuelas, de producir insidiosas formas de regulación política y moral. (Giroux, 2002: 25-37)

Ante la globalización, muchos profesionales de la educación han interiorizado que más bien poco se puede hacer ante el tamaño de la ola que parece arrasar con todo lo anteriormente conocido, ola que rompe moldes y establece otros parámetros y valores que alcanzan de lleno a lo educativo en todos sus aspectos y niveles.

¿Cuáles son los límites de la educación en ese requerimiento de ser factor de cambio social? Para quienes escribimos estas líneas, se estima que los límites están allá donde los valores llegan. Frente a la fuerza... amor. Pero con los pies en la tierra. Desde una construcción rigurosa de la pedagogía. Profesiones y profesionales que han de actuar con el «Otro» frente a profesionales que trabajan con objetos inhumanizados. La inmunidad de la comunidad (Esposito, 2003, 2005) contiene dos vertientes..., es su contingencia más grave, capaz de acabarla y al tiempo, en la dosis justa, la forma de afianzar su salud. La comunidad se pierde en ella misma. Genera espacios privados que fagocitan lo público. Una de las razones de este hecho bárbaro, casi caníbal, se produce cuando en el espacio privado se crea una razón externa al ser humano.

Por ejemplo, el dinero y la salud. Respecto al primero, la economía deja de ser una cuestión de personas y se crea un submundo de relaciones virtuales. No hay humanidad, por lo tanto, no busquemos indicios de comunidad. Se debe inyectar bumus en ella para hacerla más humana y también más munus para «obligarla»

Se entiende por «política», la dirección racional y activa de cualquier proceso social (Freire, Fiori y Fiori, 1978: 28). 
a rendir humanidad. Acerca de la salud, esta deja de ser, profesionalmente, una cuestión de personas y se crea un submundo de relaciones estatutarias. El saber se comporta como el dinero y deja de ser humano. Hay que inyectar munus y bumus para obligarla a ser y fomentar humanidad.

La educación también puede incluirse en el tándem de ejemplos. El espacio educativo deja de ser humano para definirse como técnico en un movimiento más parecido a un harakiri que a un enaltecimiento de la disciplina. Condicionantes y métodos que controlados logran un determinado producto que no es más que un intento de garantizar un resultado. Se crea un submundo de relaciones didácticas. Centrándonos en el método desaparece la ideología de la acción tras el velo de la técnica. La eficacia y la eficiencia, súmmum del positivismo, copan el interés. Hay que inyectar munus y bumus para obligarla a educar en, por y para humanidad.

\section{La pedagogía política: el empoderamiento de los valores}

La radicalización de la educación, sus respuestas y fuerzas de resistencias deben ser dirigidas por una pedagogía de acción política. No podemos dejar en manos de las y los docentes la ingente labor diaria y, al tiempo, la necesaria revisión de todas las relaciones interactuantes en el hecho educativo. Es un trabajo inabarcable. El profesorado habita un mundo donde lo urgente siempre tapa lo importante y, si no es así, aparece la burocracia para, sin decir explícitamente que no se piense, abortar en la práctica cualquier intento por falta de tiempo o la normalizada contratación precaria que anula cualquier intento de contestación.

Nos encontramos ante una campaña orquestada desde los sectores socialmente más inmovilistas de las instancias de influencia y poder real (gobierno, banca, alguno de la iglesia, grupos mediáticos) que ataca en toda regla los intereses de la universidad pública. Ello se refleja no solamente en opiniones lanzadas al vocerío, sino en estrategias para forzar que disminuya el número de profesores y aumente la ratio de estudiantes por docente, en adoptar decisiones que reducen de forma aplastante los recursos asignados a investigación (en particular en el ámbito de las humanidades y las ciencias sociales). Por otra parte, la falaz «cultura administrativa de la evidencia» fomenta un incremento alarmante de la burocracia para cualquier gestión académica, lo que ahoga poco a poco la libertad real de las personas afectadas, sean docentes, gestores o estudiantes. Además, se legitiman formas de intimidación directa o sutil hacia profesores, sindicatos docentes y diferentes modelos de asociaciones de profesores. Sin afán alguno de agotar las sinrazones de la actual política universitaria que nos toca padecer, es preciso mencionar una reducción muy preocupante del número y tipo de becas de estudio e investigación para estudiantes y jóvenes investigadores. (Hernández Díaz, 20I5)

Se necesita una pedagogía crítica. Pero desde estas líneas se aboga por denominarla, aun a riesgo de sumirla en el desprestigio actual sobre la política, pedagogía política. Porque si la política es ese espacio de toma de decisiones limitado 
por la no-posible decisión última (la impolítica), la pedagogía debe ser donde se dé cuenta de las decisiones sobre la educación limitándola por lo no-educativo. Así como en una consulta médica se da cuenta de la salud del paciente, desde su relación con la enfermedad como con su entorno por si este es mejorable en sus condicionantes hacia la persona hasta llegar al estado de no-medicina, la pedagogía, desde el espacio que le sea referente, debe dar cuenta de la educación desde su acción en las personas hasta las relaciones del entorno que influyan en dicha acción y relación, cuidándose de lo no-educativo.

Una pedagogía política capaz de encontrar los límites de la educación en relación al entorno y a las personas, definirlos y proponer las formas de alcanzarlos pero sin traspasarlos. Frente a relaciones dadas, presentar opciones de interrelaciones nuevas. Las distintas resistencias deben ser referidas y explicadas y las plausibles vías expuestas en unas prospectivas serias y bien conformadas. Se necesita una pedagogía política para hacer que la ideología esquiva y pretendidamente ausente que actualmente existe saque la cabeza y se muestre. Se exponga a ser criticada. No como ahora que simplemente parece dejar pasar el tiempo y aboga por ir asumiendo pequeñas modificaciones que nos vende como logros cuando no son más que ínfimas concesiones.

Se necesita una pedagogía política porque necesitamos un mundo nuevo no porque debamos recuperar lo perdido en los distintos momentos de crisis vividos y por vivir. Dictar nuestro futuro no desde la perspectiva de un derecho de autodeterminación que ha crecido al amparo de sentimientos conformados desde lo individual a lo colectivo ${ }^{3}$, sino desde la acción colectiva que ampara la diferencia de concepciones.

El asunto crucial en juego es cómo apropiarse, inventar, dirigir y controlar las múltiples capas de poder y de políticas que constituyen la formación institucional de la educación y las pedagogías que, frecuentemente, son el resultado de luchas deliberadas para colocar nociones particulares de conocimiento, valores e identidad. Como educadores comprometidos, no podemos eliminar políticas pero podemos trabajar contra las políticas de certidumbre, la pedagogía de terrorismo y contra una formación institucional que cierra, más que abre, las relaciones democráticas. Esto requiere, en parte, que trabajemos diligentemente para construir unas políticas sin ningún tipo de garantías que, constantemente, se cuestionan a sí mismas, así como a todas aquellas formas de conocimiento, valores y prácticas que aparecen más allá del proceso de interrogación, debate y deliberación. Contra la pedagogía y las políticas de certidumbre, es crucial, para los educadores, desarrollar prácticas pedagógicas que problematicen consideraciones de localización institucional, mecanismos de transmisión y efectos, así como hacer sitio a las críticas de los estudiantes en marcha de cómo funciona la autoridad del profesor, analizando el bagaje

3 En este sentido, se trae a colación el pensamiento de Manuel Castells, «[...] lo que comenzó como un proceso de relegitimación del estado, mediante el paso del poder nacional al local, puede acabar profundizando la crisis de legitimación del estado-nación y la tribalización de la sociedad en comunidades construidas en torno a identidades primarias» (CASTELLS, 1997: 304). 
ideológico y las investiduras subjetivas que los profesores traen consigo a la experiencia de la clase. (Giroux, 2002: 25-37)

El hecho es que, estando de acuerdo con Giroux en su análisis y propuesta general, su esquema de acción no convence en la construcción de unos cuerpos teóricos en los que basar la actividad educativa. Centrar la práctica en el profesorado como actores que generan poder en el alumnado desde unas prácticas centradas en el conocimiento y las capacidades ${ }^{4}$ es volver a darles una tarea inmersa en el «modo de hacer» que se asemeja mucho a la metodología de la educación.

Tampoco se quisiera seguir la tercera vía de Giddens (1999). No ya por la tan utilizada crítica de que más que una teoría era una mera propuesta electoralista del gobierno de Toni Blair, sino que parece buscar más un aggiornamento estructural del capitalismo del siglo XxI que una crítica sistémica a unas instituciones.

Los dos problemas más difícilmente salvables por la obra giddensiana son, por un lado, lo que se refiere a los movimientos sociales y, por otro, las consideraciones sobre la suerte de los excluidos. Respecto a los movimientos sociales tienen un papel absolutamente marginal en las propuestas de transformación social que propone Giddens. El sociólogo reconoce su importancia, incluso en la escena mundial, cuando afirma que «los movimientos sociales y otros grupos pusieron de relieve las cuestiones que caían fuera de la política socialdemócrata tradicional -la ecología, los derechos de los animales, la sexualidad, los derechos de los consumidores y muchas otras» (Giroux, 20or: 63). No obstante, no duda en tratarlos como grupos de interés corporativos, los remite a una esfera subpolítica y estima que «su importancia es, en gran parte, simbólica: presionan para incluir asuntos en la agenda política, y dan forma concreta a los conflictos que les rodean» (Giroux, 200I: 66). De este modo deja en claro que para su perspectiva tercerista lo político partidario es preeminente, lo que pone en entredicho muchas de sus apreciaciones referidas a las políticas de la vida o a la real importancia que pueden llegar a tener, en la perspectiva de una posible emancipación social, en todos los esfuerzos tendientes a la renovación de la sociedad civil.

Entendiendo desde estas líneas que los movimientos sociales son una referencia principal en el común enfoque intelectual, moral y de acción, que podemos definir como crítico, transformador o emancipatorios. Se entiende la educación transformadora ligada a la acción de los movimientos sociales liberadores y al conocimiento crítico. Forzosamente han de existir diferencias según nos hallemos en el campo de los movimientos sociales, en el de la ciencia social crítica o en el

La «pedagogía fronteriza» reconoce el conocimiento y las capacidades como sus principales contenidos educativos siempre y cuando permitan o generen «las oportunidades de armar ruido, de ser irreverentes y vibrantes». En ese sentido, el conocimiento, las destrezas y los valores se convierten en contenidos educativos necesarios para que el alumno pueda negociar de manera crítica los límites culturales que le ofrece la sociedad y, en consecuencia, para proceder a transformar el mundo en que vive (Giroux, 200r: 8).

Lo que no quiere decir, obviamente, que todas las personas que lo compartan tengan exactamente la misma ideología o la misma toma de postura en cada asunto concreto. 
de la educación, pero defendemos que, con diferentes puntos de partida y actos concretos, ha de haber unos hilos que conformen un conductor común, y que, además, la filosofía de actuación se enriquece si tenemos en cuenta en cada campo las aportaciones de cada uno de los demás. Desde esta visión, la educación no asume una posición subalterna-enseñar lo que otros descubren o defienden-, puesto que el mismo proceso de acción sociopolítica y de conocimiento participante también tiene un componente cultural o educativo. La educación, por su parte, no se considera de ninguna manera al margen de la sociedad en la que interviene.

Los movimientos sociales constituyen un referente, como dicen Anna Ros y José A. Antón,

[...] [la sociedad] demuestra una pluralidad organizativa importante que muestra no solamente, la diversidad de enfoques de los problemas y conflictos que la aquejan, sino también los cauces plurales posibles para resolverlos. Esta «posibilidad de lo plural» sería precisamente uno de los aspectos donde han crecido las ONG que demostrarían no sólo la posibilidad, sino también la necesidad de romper el monopolio del saber social. (Valero y Ros, 2003: 5I-70)

El otro problema referido son las consideraciones de Giddens sobre la suerte de los excluidos. La justicia social y la política emancipadora constituyeron la esencia de la socialdemocracia clásica. Hoy, estos postulados pretenden ser actualizados por la «Tercera Vía» en un marco creciente de polarización social. Sin embargo, Giddens no reduce su perspectiva de la exclusión a términos meramente económicos o distributivos. Según él, «la exclusión no se refiere a niveles de desigualdad, sino a mecanismos que operan para apartar a grupos de personas de la corriente principal de la sociedad» (Giddens, 1999: 125) ${ }^{6}$. Pero a pesar de este reconocimiento a los desheredados del sistema, en su propuesta no existen políticas concretas para llevar adelante su integración.

El no estar convencidos de que los autores comentados hayan expresado una solución no es óbice para dejar la senda marcada por ellos y por tantos otros no nombrados. Desde una posición ética que deja sin programar la obsolescencia del saber acumulado en su relato, pero desde la conciencia de que sí tiene presente que la tiene. Una posición que sin dejar de utilizar sus incipientes posibilidades, tiene claro que ya comienzan a expirar. Una posición que no deja de apostatar de sus posturas porque sabe que solo son postureo. La herejía incesante sobre cualquier visión con intenciones de constituir ortodoxia. Una perspectiva desde

6 Este vacío programático da pie a la crítica que Touraine lanza contra la Tercera Vía, justamente, por la incapacidad manifiesta para atender y satisfacer la demanda de integración de los sectores excluidos (TouraINE, 1999: 96-97). Cuando Giddens busca aumentar la apuesta por los afectos solidarios de los individuos o incrementar la inversión posmaterialista para la renovación de la sociedad civil, entra en abierta consonancia con los intereses neoliberales, que solo quieren reducir la carga económica del Estado para mantener los equilibrios macroeconómicos, esos de los que Giddens nunca habla a la hora de evaluar los efectos de sus propuestas políticas para evitar la exclusión. 
la comunicación, como eje vertebrador del hecho educativo ${ }^{7}$, que, «[...] supone la aceptación de que nadie tiene la solución sobre el qué, cuándo y cómo enseñar y evaluar, pero que se pueden ir construyendo soluciones provisionales, siempre mejorables posteriormente, a través de la dinámica intersubjetiva» (Ayuste, Flecha, López Palma y Lleras, 1994: 8I).

Una pedagogía política permitiría construir un ente flotante donde agarrarse en caso de riesgo. Un ente temporalmente flotante y así debe ser. Una pedagogía política que nazca muerta, en un camino constante hacia los abismos porque ya es tarde para este presente pero que deja nociones de flotabilidad en aquellos y aquellas que han sido conmovidos por ella. Una pedagogía política que ampare a las personas desde un amor generador de pasiones y compasiones frente a los seres humanos forzados y sus circunstancias. Un amor contra la fuerza pero desde la fuerza. La fuerza de las distintas razones conjugadas para realizar un discurso. La fuerza de lo colectivo desde el compromiso con objetivos considerados importantes, pero más aun con relaciones consideradas vitales. Un colectivo que tendrá lugares diversos para conformar los relatos, multitud de relatos que responderán, desde la heterodoxia reconocida, a la unicidad pretendida.

La vida entendida como interacción. No existe acción, no existe movimiento, no existe pasión. Debemos cambiar todo ello con el valor de la comunidad y en este campo sí que hay espacio para la educación y la pedagogía. La pedagogía política no es el munus de la comunidad. Es el com. Así debemos lograr la comunicación, la conmoción, la compasión..., objetivos imposibles a no ser que se recoja el guante del pensamiento de la alteridad,

[...] frente a la voluntad racionalizadora de las diferencias, el pensamiento de la alteridad apuesta por una «política de los espacios» en la que el accionar de los sujetos se configure de múltiples formas con pulsiones y efectos liberadores: ya no bajo la búsqueda de los fines últimos en torno a los cuales promover el consenso universal respecto de la sociedad ideal, sino como prácticas de resistencia que fracturan las codificaciones institucionales de poder-saber. Prácticas cuyas condiciones de posibilidad son impensables sin la irrupción de la pluralidad de voces de aquellos que han sido privados de su propia voz para que otros hablen en su nombre. (Skliar y Téllez, 2008: 135)

Una pedagogía política que abra espacios para los no tenidos en cuenta y que genere posibilidades de comunicación en procesos de empoderamiento.

Los procesos educativos siempre han estado conexionados con los procesos comunicacionales. Es más, sin comunicación no hay educación posible, pudiéndose entender toda acción educativa como un proceso de comunicación. No se puede olvidar que la enseñanza-aprendizaje se desarrolla básicamente a través de un importante proceso de trasmisión y de comprensión de la información o mensaje. La aportación de la teoría de la comunicación a la educación consiste en explicar los distintos elementos como el efecto, los tipos, las modalidades o el propio lenguaje utilizado que interviene. A través de estos elementos se ha hecho posible el entendimiento de una nueva dimensión y perspectiva de los procesos educativos. 
Con unos significados y alcances de la idea de empoderamiento infinitamente más amplios que la concepción teórica del mismo․ Se trata de utilizar una dirección ideológica del término y reclamar que -frente al sufrimiento por el ejercicio de un poder que no tiene en cuenta a todos y todas y al tiempo la construcción de la creencia generalizada de que es algo lejano que detentan los otros, los poderosos- el poder, como potencial a realizar en el ser personal y comunitario, reside en nosotros, en la gente común, y se puede hacer efectivo si, siendo consciente de ese potencial genérico, la gente -la comunidad- actúa para hacerlo realidad. Esta es una clave, y la podemos resumir prosaicamente afirmando que el poder es, cuando menos, un medio esencial para el desarrollo humano.

Ya se ve, entonces, que el empoderamiento no es solo un concepto operativo, sino también un valor básico (aunque, como medio, de forma instrumental) del campo comunitario y, en consecuencia, la base de un cambio cultural potencialmente revolucionario al alcance de la pedagogía política y enfrentada a la visión psicologizante que aboga por la referencia individual, asumiendo que lo colectivo será la suma de sus resultados'.

La pedagogía política se abre a las aportaciones psicológicas, pero como medios para abrir la posibilidad de cambiar la concepción que los humanos tenemos de nosotros mismos (y de crear nuevos modos de actuar) elevándonos a la calidad de sujetos agentes de nuestros propios fines y proyectos humanos que son comunitarios, en lugar de ser servidores, agentes de otros. Ese es, naturalmente, el significado ideológico del empoderamiento que en el campo social la acción política y social desde abajo (movimientos sociales, tercer sector, etc.) se suma -pero no complementa pues lo hace a través del conflicto dialéctico- a la acción formal, desde arriba.

Ahora bien, la pedagogía política provoca en la educación una relación dinámica y dialéctica entre los valores y los conocimientos. En un mundo donde se dan por terminadas las ideologías, donde se afirma que lo que hay es mejorable en parcialidades estancas porque es lo mejor que puede haber y que todo fallo del sistema se debe a fallos humanos en la acción del mismo porque ya lo pensado está en su culmen, la pedagogía política debe empoderar a los valores. Darles voz porque han sido silenciados, manipulados y vilipendiados. La educación, que era un reducto de posibilidades de dinamización social, ha entrado en el juego

El empoderamiento, como concepto ya asumido por la hegemónica ideología neoliberal y trabajado teóricamente por sus acólitos, significaría «un incremento de la capacidad individual para ser más autónomo y autosuficiente, depender menos de la provisión estatal de servicios o empleo, así como tener más espíritu emprendedor para crear microempresas y empujarse a uno mismo en la escala social. También implica mejorar el acceso tanto a los mercados como a las estructuras políticas, con el fin de poder participar en la toma de decisiones económicas y políticas». En el Diccionario de Acción Humanitaria y Cooperación al Desarrollo de la Universidad del País Vasco. Disponible en línea: http://www.dicc.hegoa.ehu.es/listar/mostrar/86. Consultado el o5/08/2015.

9 Hay que decir que la psicología ha hecho suyos muchos de los conceptos emergidos desde otros ámbitos y hasta ha sido considerada (como ya señaló el psicólogo George Miller en i969 y, más explícitamente, el filósofo Alasdair McIntyre en 1985) como ideología central del mundo moderno. 
de los espejos. Se ha visto tantas veces modificada que ahora no sabe cuál es su verdadero ser. Las imágenes han hecho que del parecer se construya, a medida de los intereses de grupúsculos con poder, unas definiciones teóricas que, en vez de explicar el mundo, lo definen.

Un mundo definido por las teorías que se esconden en la virtualidad creada necesita de una discriminación positiva hacia las posibilidades de cambio. La pedagogía política ofrece posibilidades de pensar las otras vías. Es un paso anterior puesto que genera las situaciones del pensar y, por qué no, del pensar de otro modo.

La ciencia ha construido un modo de violencia hacia los valores. Los conocimientos se instauran y asfixian a los valores exigiendo datos de corroboración a los que responder con la historia, la filosofía, el arte o la pedagogía no parece bastar. El positivismo deja tras de sí huellas de víctimas incontables que no han dejado de respirar por sí mismas sino ahogadas en las normas científicas. Y ahora hablamos de conceptos que han ido mutando al son de quienes ejercen poder y con la complicidad de los mansos y mansas. Si se pone de ejemplo la actual política de diversidad, podemos decir, como Skliar y Téllez,

[...] la diversidad se ha convertido en una palabra de orden (esto es, que se produce desde el orden y que por lo tanto, profesa un orden) y que su simple mención constituye ya una virtud democrática, política, cultural y pedagógica, imposible de ser puesta bajo sospecha. Así, los discursos que hoy se reúnen en torno a la idea de diversidad, de muy variado origen y, en ocasiones, de muy dudosa configuración teórica, ostentan ser los únicos para una referencia intachable acerca del otro. (Skliar y Téllez, 2008: 108)

Llegados a este punto quedaría hablar del modelo de ejecución del proyecto educativo. Se debe huir del victimismo de la pedagogía y afrontar el reto desde una resiliencia del saber educativo. La capacidad para crear estructuras de acción no debe ponerse al servicio de la revancha contra institución alguna ${ }^{10}$. La acción proactiva es la única capaz de servir como elemento de flotabilidad para todas las personas interesadas en un cambio social al tiempo de ir creando una imagen social de la educación como un elemento necesario para una mejora de la calidad de vida común.

Al tiempo se deberá evitar la culpabilización. La educación no deja de ser una parte de un todo que ya inquiere su modus operandi. No poder crear alternativas

1o La queja del profesorado está muy extendida, identificando casi siempre a las familias, a los alumnos y a la sociedad con el origen de un mal que parece haber arraigado en el sistema. Los profesores rara vez se autoinculpan de un fracaso que tiene, sin embargo, su expresión más ostensible en su periódica emisión de calificaciones, supuestamente fruto de un juicio realista, experto, objetivo, ponderado. El docente, haciendo gala de un victimismo que lo libera de casi toda responsabilidad, se suele colocar a una prudente distancia de este problema, del que o no se siente agente, o en todo caso solo subsidiariamente. Sálvense, desde luego, muchas excepciones, pero la regla es esa. La cultura docente - sobre todo de secundaria - se sigue atrincherando tras su habitus, ajena a la evidencia de sus incapacidades y tercamente reacia a los cambios y, desde luego, a la autocrítica. 
fuera de las directrices impuestas no es más que cumplir con el plan establecido. La propia política de sobredotación, dentro de la de Necesidades Educativas Especiales (NEE), es un claro ejemplo de ello ${ }^{\text {II }}$.

Ahora bien, si se huye de la culpabilización más se ha de huir de la sobreprotección. No puede haber un cambio desde debajo de las alas del sistema ${ }^{12}$. No puede pretender una pedagogía que se defina como política que, bajo el amparo de una forma de pensar, aparezca otra distinta que se declare deconstructora y constituyente. Para poder pensar algo diferente primero hay que pensar. Los espacios herejes han de brotar en la institución para que las herejías mismas permitan apostatar como forma de progreso.

Como se puede observar, los distintos ejemplos referidos se componen de actos, modos y políticas educativas que no conforman un cuerpo con enjundia, sino que se comportan como nano-entes dentro de un sistema inabarcable por uno solo de ellos.

La fragmentación del hecho educativo en políticas educativas lleva a enfrentar problemas específicos sin pensar en la repercusión que tienen en el todo. Cada dirección general de las distintas áreas de la Consejería de Educación y Universidades tiene encomendada la tarea de sacar adelante dicha área específica. También sucede con los distintos vicerrectores y vicerrectoras de cada universidad española y europea. Un trabajo ingente que se coordina bajo el auspicio de una persona figurante como titular tras una reunión de carácter semanal normalmente.

Políticas educativas que edifican una educación a modo patchwork, que en español sería retales, chapuza o trabajo irregular, que, sin embargo, sí que permiten

II El tratamiento inicial del concepto de «necesidades educativas especiales» recogido en la LOGSE se concretó, administrativamente, con la publicación del Real Decreto 696/1995, de 28 de abril, de ordenación de la educación de los alumnos con necesidades educativas especiales, dedicado, en gran medida, a la regulación y adaptación al nuevo marco normativo LOGSE de lo que hasta entonces había sido objeto de regulación del R. D. 334/1985, de 6 de marzo, de Ordenación de la Educación Especial, y que se dirigía específicamente a la regulación de la atención educativa del alumnado con discapacidad a través de lo que había sido el programa de integración desarrollado por el MEC. Podemos afirmar que con este Real Decreto se consolidó la interpretación restrictiva del concepto de NEE ya iniciada con el planteamiento LOGSE. Obsérvese que, por parte de la Administración, se estaba definiendo «la ordenación de la educación de los alumnos con necesidades educativas especiales». El propio título del Real Decreto ya resulta, en cierta medida, incompatible con los postulados de fondo asociados al concepto de «necesidades educativas especiales». Desde esta perspectiva no tendría demasiado sentido hablar de una educación para alumnos con necesidades educativas especiales, objeto de una regulación propia y diferente de la contemplada para el resto de los alumnos. En todo caso, las posibles pautas, apoyos o recursos específicos que el sistema educativo debe proveer para hacer frente a esas necesidades deben buscar, precisamente, que los alumnos que las requieran no se vean apartados de las fórmulas educativas previstas a nivel general o sometidos a una educación específica diferente de la del resto.

${ }_{12}$ Una de las políticas o usos de sobreprotección se dan en el gremialismo docente universitario que redundan formas de pensar al no permitir la entrada de nuevas formas de planteamiento. Así, una de las propuestas más importantes es la de ampliar el background formativo de los profesores que conforman las distintas áreas y realizar una apuesta clara por la interdisciplinariedad, para lo que habría que acabar con el gremialismo. 
evaluaciones completas del sistema como mecanismo de «sálvese quien pueda» porque cada cual debe responder por el trozo que le es encomendado. Y quien ostenta la titularidad de cada parte, que en teoría coordina la acción, ni siquiera sirve para representar a la institución en su conjunto y menos sirve para definir la acción conjunta de esta.

Es por ello que una pedagogía política pudiera dar forma o con-formar la acción educativa desde la visión política, desde la toma de decisiones, desde la visión holística que propone.

\section{La pedagogía política como «agencia» educativa}

Llegados a este punto, diremos que no se quiere pecar de inocentes en lo que la realidad contrapone a los deseos expresados. No se está hablando de un método educativo concreto, sino de una filosofía pedagógica que, eso sí, requiere una implementación coherente, o bien, si empezamos por el otro lado del hecho educativo, de una práctica que tiene que ver con referentes emancipadores. Se trata, por tanto, de un enfoque que admite y promociona la pluralidad dentro de sí, incluso en las denominaciones hacia sí mismo.

Las principales explicaciones sobre la acción política dentro de la ciencia social predominante se han movido a lo largo de un eje con dos posiciones extremas en lo que se ha llegado a considerar como la cuestión básica de la teoría social contemporánea: los debates sobre acción (agency, en inglés) y estructura. En síntesis y de manera muy simplificada, se han enfrentado las posiciones estructuralistas y funcionalistas, frente a otras mayormente individualistas-subjetivistas. Así, en un extremo se pueden encontrar las posiciones que hacen desaparecer toda posibilidad de agencia -acción- como propiedad del sujeto, reduciendo esta a un mero efecto de las estructuras y al sujeto como un efecto de ellas. En el otro extremo, la posición individualista-subjetivista de algunos enfoques que mantienen una concepción de los individuos como agentes autónomos capaces de abstraerse de sus constricciones estructurales y dirigir la acción de manera racional -agenciarse la acción-. Ambas posiciones son partícipes de un mismo movimiento esencialista que hace descansar en un lugar privilegiado, un origen, un fundamento, a la acción humana (en la estructura o en el sujeto racional que puede abstraerse de todo contexto de existencia).

A la vez y como alternativa a estas dos posiciones extremas, se han desarrollado interesantes cuerpos teóricos que tratan de encontrar un punto intermedio que supere el dualismo entre estructura y acción. Entre los más destacados podríamos citar la teoría de la estructuración de Anthony Giddens (1995) y el estructuralismo genético de Pierre Bourdieu (2000). Ambos enfoques contribuyeron a reubicar -frente al estructuralismo del que en cierta medida son deudores- el concepto de acción social como lugar central en la sociología contemporánea. Ambos se distancian de una representación cerrada de la estructura social, rescatando cierta noción de sujeto que poco tiene que ver con un sujeto trascendental metafísico o 
racional individualista. El sujeto-agente es un actor situado en contextos concretos estructurados y estructurantes.

Nuestra posición en la defensa de una pedagogía política, que toma muy en cuenta algunas enseñanzas de estas perspectivas ${ }^{13}$, parte de la constatación de que las estructuras nunca pueden ser consideradas como un sistema cerrado como totalidad; así como tampoco el sujeto nunca puede ser una identidad plena y estable. Sin embargo, estos dos enfoques, situados al fin y al cabo dentro de la ortodoxia del pensamiento social, siguen manteniendo algunos de los binarismos ontológicos heredados de la modernidad ilustrada (sujeto vs. objeto, social vs. natural, simbólico vs. material, mente vs. cuerpo, conciencia vs. realidad, entre otras) que sostienen como dos polos diferentes, aunque interactúen conjuntamente, sujeto y estructura. En nuestra opinión, una mirada analítica más adecuada y políticamente más eficaz sobre la producción de efectos en el mundo requiere del desbordamiento de las dicotomías ontológicas de la modernidad. Se trataría de moverse hacia concepciones ontológicas menos «sustancialistas» y más radicalmente relacionales que, además de recoger el paso adelante que supone el reconocimiento de la mutua constitución entre sujeto y estructura, abandonen la consideración de ambos como naturalezas diferentes pero irremediablemente entrelazadas.

Llegados a este punto contamos ya con elementos suficientes para proponer el abandono del lugar del sujeto como elemento central para referirnos a la acción pedagógica política. Las razones para este desplazamiento no son solamente teóricas. Creemos que la teorización sobre la acción pedagógica política es también una parte de esta y que, por tanto, puede y debe acompasarse a las nuevas formas de acción pedagógica política postpositivista, postmoderna, postidentitaria, que están emergiendo en nuestro contexto contemporáneo. Frente a esta prioridad humanista y subjetivista vamos a dirigir la atención hacia la agencia (Ema López, 2004).

El término inglés agency ha sido traducido al castellano como agencia, acción o actuación. Para estas dos últimas palabras existen, sin embargo, otras expresiones en inglés. Así que agency necesariamente se refiere a algo diferente a lo que denominamos en castellano acción o actuación. Aunque nuestra propuesta parte de la tradición de usos en la que se ha producido, su utilización en este contexto destaca y propone algunas cuestiones que pueden distanciarse de sus lecturas más ortodoxas. Así, se trae a este trabajo este término fundamentalmente por cuatro razones que desgranaremos.

En primer lugar, porque nos permite entender la capacidad de actuar (agencia) no como propiedad individual, sino como posibilidad (poder hacer) compartida. Esto implica vincular la capacidad de acción con una concepción relacional del poder; y no entender esta como un volumen de almacenamiento propiedad de un sujeto-agente.

${ }^{13}$ Aceptando la posible incoherencia existente en la utilización de las bases teóricas de Giddens habiendo desechado su propuesta práctica anteriormente en el principio de este trabajo. 
Sin duda la teoría de la -doble- estructuración de Anthony Giddens es una referencia ineludible para referirnos a la agencia. En la introducción de La constitución de la sociedad este autor utiliza el término de agencia (agency) en vez de utilizar «acción» para destacar cómo la ejecución de la acción es más una cuestión que se refiere al poder que a la intención particular del agente. Así, considera a la agencia como la capacidad de hacer cosas, no a la intención del individuo de hacerlas.

La agencia se refiere no a las intenciones que la gente tiene en hacer cosas, sí a su capacidad de hacer esas cosas en primer lugar (por eso la agencia implica poder). Agencia se refiere a los eventos de los cuales un individuo es un autor, en el sentido de que un individuo podría, en cualquier fase de una secuencia dada de conducta, haber actuado de manera diferente. (Giddens, 1995: 9)

Para este autor el sujeto humano sigue siendo la referencia privilegiada para pensar la acción y aunque el uso del término agencia permite considerar que el agente no sea solamente un individuo (puede ser un colectivo) y aunque su mirada sobre el sujeto-agente es suficientemente flexible para incorporar las críticas al debilitamiento (post)estructuralista de este, sin embargo, la acción es entendida como la actuación de un agente en el mundo para introducir novedad en él.

De cualquier modo, del trabajo de Giddens se recuperará la dimensión de poder, de potencia, para proponer nuestro propio uso del término agencia. Sin embargo, queremos distanciarnos del privilegio de lo humano para definir la idea de acción desde un agente que actúa, pero manteniendo la idea de producción de novedad. Así, matizamos la idea de agencia como capacidad del agente. No se trata de considerar al sujeto humano como in-capaz para actuar, sino de entender de manera relacional esta capacidad. En este sentido, nos parece conveniente recuperar la idea de capacidad como posibilidad (poder hacer) más que como volumen de almacenamiento, como si la agencia se acumulara en un depósito para ser liberada posteriormente en la ejecución de la acción ${ }^{14}$.

La agencia implica una capacidad de/para actuar. Retomando el término inicialmente planteado por Aristóteles, la agencia se refiere a una potencia para la acción. Entendiendo en este caso la potencia como la posibilidad del despliegue de una transición hacia un acto $^{15}$. Pero lejos de compartir las interpretaciones de

I4 Esta idea de capacidad aparece también en el ámbito del Derecho como la característica que habilita a un individuo como agente de relaciones jurídicas, como sujeto de derechos, en tanto que capaz. Esta lectura jurídica nos permite incorporar un elemento interesante para reforzar la dimensión relacional sobre la que estamos insistiendo. Los derechos y la constitución como sujeto-agente no son una propiedad del individuo. Aunque es necesaria la concurrencia de este, no existiría sin una ley que le precede y le habilita como tal sujeto-agente. No hay sujeto «capaz» sin ley.

${ }_{15}$ El concepto de potencia fue presentado por primera vez por Aristóteles y remite a lo posible. En su libro IX de la Metafísica (disponible en http://filosofia.org/cla/ari/azcio.htm), Aristóteles elabora una explicación del cambio que recoge la multiplicidad del ser, la posibilidad de ser de muchas maneras sin dejar de ser, frente a concepciones anteriores que concebían al ser como uno, acabado, unitario y perfecto. Se trata de elaborar una propuesta ontológica que permita entender un mundo 
la potencia como el despliegue de algo ya determinado y programado, la potencia se refiere a la introducción de un efecto no determinado necesariamente, sino a la incorporación de novedad en el contexto normativo que supone lo social. En este sentido, la agencia nos remite a nuestra idea de acto político. La agencia como potencia se refiere a la capacidad-posibilidad de producir un efecto de novedad frente a un trasfondo de constricciones normativas.

No nos estamos refiriendo a la agencia como una propiedad individual o poseída por un agente, sino a la interrelación de elementos que pueden permitir la emergencia de un acto político. Por eso hablar de capacidad-posibilidad tiene que ver con la potencia y el poder. Y entendemos este como algo que circula en las relaciones (Foucault, 1977), no como propiedad almacenada en los individuos. Así, atendiendo al poder, la agencia como potencia antecede al sujeto-agente y a su control reflexivo de la acción (Giddens, 1995), es más primaria y básica, en tanto en cuanto el agente, al constituirse como tal en la acción, es precedido por el poder ${ }^{16}$.

cambiante e inestable. Así, explica el cambio mediante la relación potencia-acto. En la que la potencia indica una posibilidad de ser o no ser de un modo concreto, pero no la obligación necesaria de ser de un modo concreto. Es decir, la potencia no es la anticipación de algo que necesariamente será de una manera determinada. No estamos hablando del despliegue de una racionalidad que rige el cambio, sino de la constitución del ser en la tensión potencia-acto como marca de la necesidad de la contingencia y la contingencia de la necesidad. Para este trabajo nos parece especialmente relevante considerar esta relación potencia-acto como una tensión que no culmina satisfactoriamente; es decir, que no es gobernada por la necesidad o por fundamento último ninguno que procure un cierre. En palabras de José Luis Pardo: «[...] todas las desventuras de la potencia proceden del simple hecho de que es potencia, sólo potencia y no actualidad, es decir, del hecho de que no es todo lo que puede ser, de que le falta algo para ser plenamente lo que es. Tener potencias es, en este sentido, tener un déficit de actualidad, y estar abocado a hacer un esfuerzo por cubrir ese déficit, lo cual ya es en sí mismo una desventura. Se diría, igualmente, que la desventura originaria no es del acto ni de la potencia, sino que consiste en la escisión entre acto y potencia, es decir, en el hecho de que las cosas no sean plenamente lo que son» (Pardo, 2002: 57).

La idea de potencia nos enfrenta radicalmente con las de fundamento último y necesidad y nos permite entender los fenómenos sociales como abiertos, precarios e inestables ( $y$, por lo tanto, marcados por lo político).

${ }_{16}$ No existe sujeto-agente antes del poder, de tal manera que pueda ser coaccionado por este. El poder, siguiendo a Foucault, no es un poder censor y limitativo sobre algo que ya existe, es productivo. Así, el poder no solo actúa sobre el sujeto, sino que permite actuar al sujeto, otorgándole existencia (Butler, 20oI). Esta paradoja atrapa a la acción y no puede ser erradicada. El agente es efecto del poder y simultáneamente condición de posibilidad de un poder actuar y hacer (no infinito, sino condicionado y parcial, pero, al menos, sí capaz de generar otros posibles que los que marca el poder que le ha constituido). El poder que el agente pone en práctica es posibilitado por el funcionamiento anterior del poder, pero en última instancia no está determinado por él. Por eso decimos que la potencia desborda al poder. Porque el poder marca los posibles del acto político, pero la potencia trata de ir más allá como movimiento instituyente dirigido a lo imposible. El poder que constituye al sujeto es condición de posibilidad del poder que el sujeto ejerce, pero no lo controla todo. No se trata de un proceso de vasos comunicantes que sacan, por un lado, lo que entra por otro. Solo manteniendo una mirada individualista sobre la acción podríamos sostener que el poder que constituye al sujeto se transforma, así linealmente y como por arte de magia, en el poder que el sujeto ejecuta. No estamos hablando de entidades previas al poder que luego lo despliegan en sus relaciones, sino 
La segunda de las razones es porque nos permite entender la acción como mediación entre flujos de acciones y vincular esta mediación al compromiso ético-político con una ubicación en el espacio social determinada -frente a las concepciones objetivistas de la acción que pretenden hablar desde ninguna parte-Es la idea de (inter)mediación. En castellano el término agencia es empleado también para referirse a entidades mediadoras que facilitan el ejercicio de determinadas acciones. Véanse, por ejemplo, las agencias de viajes o las agencias matrimoniales (Casado, 1999). Así, podemos entender la agencia como algo que está/es en el (inter)medio, en medio de los flujos de acciones. Algo que desvía, traduce y conecta prácticas. El mediador no es totalmente exterior a lo mediado, también forma parte de ello. Además es transformado y re-creado en su mediación. La agencia como mediadora es lo que permite que la intersección de flujos de prácticas semióticas y materiales se concrete en actos.

Esta consideración de la agencia como inter-mediadora nos permite destacar dos ideas interesantes. Con la primera insistimos en la dimensión relacional (inter)presente en toda acción. Actuar es hacer con otras, la acción no es un producto individual y la agencia -como capacidad posibilidad-es también compartida. Como veremos más adelante, radicalizar este relacionalismo nos va a permitir incorporar otras agencias no humanas a la producción de efectos en el mundo.

La segunda nos permite escapar tanto de la mirada moderna que fundamenta la acción política en un sujeto trascendental como de algunas posibles lecturas postmodernas que, en la negación de los fundamentos trascendentales, abandonan también fundamentos locales, parciales y situados. Y es que precisamente el concepto de agencia apunta a un lugar, a la inevitabilidad de estar situada. La agencia, en tanto posibilidad y potencia, no parte de cero, está siempre ubicada en una posición en el espacio social, en una trama de relaciones. Aunque esta no suponga un fundamento último para la acción, sí marca el contexto de acciones posibles. Así, frente a la preeminencia de posiciones epistemológicas ontológicas y políticas neutrales y objetivas, la agencia en tanto que mediación nos permite atender a los lugares de enunciación y localizar y comprometernos con ellos como fundamento ético-político precario e inestable para la acción, pero de cualquier manera situado y no neutral ${ }^{17}$.

Un tercer aspecto al que nos remite el concepto de agencia es que nos permite incorporar la noción de responsabilidad como construcción semiótica y material de una entidad, acontecimiento o práctica como elemento dinamizador de la acción.

del poder que circula en las relaciones y que no es una propiedad de un agente único. La capacidad de acción, la agencia, en tanto que potencia, es decir, de posibilidad de ejercer/subvertir el poder, no está depositada en un actor único como en un almacén que se vaciaría al actuar.

${ }_{17}$ Para profundizar en esta cuestión se pueden consultar los trabajos sobre los conocimientos situados de Haraway (1995) y el uso dentro del feminismo de las «políticas de la localización» en Casado (1999). 
Relacionada con la consideración de la agencia como mediación situada, podemos considerar a esta como lugar de atribución de responsabilidades sobre la acción. No estamos hablando ni de causalidad ni de determinismo, sino del reconocimiento/construcción de un elemento movilizador de la transición de la potencia al acto concreto. No hablamos de una esencia o fundamento último para la acción, sino de la delimitación de determinadas condiciones de posibilidad como responsables de un acto concreto.

Se propone el término de agencia para referirnos más que a una entidad -un agente, un «quién» o un «qué»-, a un proceso -a un «cómo»-. Para dar cuenta de este proceso vamos a completar nuestro concepto de agencia incorporando algunas ideas de Gilles Deleuze y Félix Guattari para definir agencia como «territorialización de una potencia» ${ }^{18}$. Estos autores emplean el concepto de territorialización para referirse al movimiento que hace territorio, que codifica, que ordena, que estructura. Un movimiento de territorialización siempre lleva asociados otros de desterritorialización y reterritorialización. Es decir, supone un cuestionamiento y un reordenamiento simultáneamente del contexto en donde opera. La agencia es lo que nos va a permitir que la potencia se territorialice en un acto concreto (que subvierte-cuestiona y que construye-ordena). Este movimiento se produce a través de la mediación de diferentes elementos que dinamizan y movilizan; pero que también son a la vez constituidos en ese movimiento. Su trabajo es mediar y medrar, facilitar/dificultar, desviar y canalizar; en definitiva, establecer conexiones y desconexiones. La emergencia de estos elementos en el despliegue de una acción permite su señalamiento como responsables.

Lo relevante es que ya no podemos empezar hablando de las entidades para luego ver cómo actúan en cada contexto. Son emergencias locales en contextos delimitados, en los que se constituyen, de manera situada, relaciones, conexiones, entidades... como funciones específicas dentro de un acto concreto. No estamos proponiendo la incapacitación para la acción política de las personas, al contrario, se trata de comprometernos con nuestro modesto lugar de enunciación en una trama de relaciones en la que «nuestras» acciones son producidas por, y productoras de, las articulaciones con otros (acontecimientos, agentes, entidades, prácticas, objetos, deseos...) ¿Hasta qué punto pueden ser consideradas entonces estas acciones como sólo «nuestras»?¿Cuál sería el criterio que marcaría su propiedad y su autoría?

Preguntarnos desde el concepto de agencia por la responsabilidad de la acción no nos obliga a buscar un actor único, ni a optar por un punto de vista estructuralista o subjetivista, sino a atender a esta como algo que funciona circulando entre relaciones y que se concreta territorializándose en entidades, acontecimientos, prácticas, etc. En este sentido, condiciones estructurales y capacidades del sujeto se tornan indistinguibles al ser constituidas conjuntamente como elementos dinamizadores de la territorialización de una potencia.

18 Esta formulación de la agencia como «territorialización de una potencia» corresponde a Francisco Javier Tirado. 
Como cuarto y último apunte sobre el concepto agencia afirmamos que subvirtiendo la distinción entre sujeto y estructura nos permite entender la capacidad de actuar como capacidad de generar conexiones entre entidades y procesos heterogéneos. Esta visión relacional sobre la responsabilidad permite entender la acción como cuestionamiento, re-construcción y generación de conexiones.

Se ha vinculado la agencia a la posibilidad y a la potencia. Se entiende esta potencia no como el previo causal de un acto que culminaría de manera necesaria en una existencia determinada. Si el movimiento de la potencia al acto fuera la respuesta cerrada a una ley última no habría entonces potencia, no habría posibilidad. Cuando se habla de posibilidad nos referimos a un camino, que puede ser o no ser recorrido ${ }^{19}$. Si algo puede ser o no ser es porque su existencia no está dada de manera definitiva y, en cierto sentido, la posibilidad de ser de una manera diferente sigue presente en el acto (Pardo, 2002). Este residuo de (im-)posibilidad viene marcado, en nuestra opinión, por la dimensión relacional de toda presencia. Algo es de alguna manera concreta porque está sostenida en tramas de relaciones y conexiones. Estas relaciones son las que le permiten existir, pero también las que le obligan a que esta existencia sea imperfecta y tenga siempre la presencia de otros como bloqueo de su actualidad plena y, simultáneamente, como condición de su presencia.

En este sentido, el término potencia nos remite a un acto creativo que desborda las constricciones dadas para tratar de fundar algo no previsto ni dominado totalmente por el juego de lo posible, algo, en cierto sentido, imposible. De este modo podemos decir que la potencia desborda al poder; es decir, a las constricciones presentes en un contexto-momento concreto. Así, podemos caracterizar la emergencia de un acto político como movimiento en esta tensión posible-imposible.

Por tanto, que el mundo no esté definitivamente dado y no obedezca al despliegue de ninguna esencia pre-determinada significa sobre todo que toda presencia se constituye en relaciones. Así, nada es por sí mismo al margen de las relaciones en las que está presente. En este sentido es en el que podemos considerar que actuar es modificar relaciones. Como hemos visto, el poder emerge en la circulación de las regularidades de las relaciones sociales y la potencia trata de desbordar y de salirse de la norma que propone el poder. La capacidad de actuar, la agencia, es por tanto la posibilidad de escapar a la norma para tratar de fundar otra regla. Está fundación será nuevamente una posibilidad de desarrollar el poder de la regularidad y podrá ser nuevamente cuestionada y desbordada.

En la medida en la que las acciones significan una incorporación de novedad en un orden de relaciones dado, la novedad que se introduce son nuevas formas de relacionar, de conectar y desconectar. Así, la agencia es potencia para la creación

19 Así Aristóteles afirma que «toda potencia es también potencia de lo contrario» (Metafísica IX, 8, I05ob8, disponible en http://filosofia.org/cla/ari/azcio25I.htm). Si un acto puede ser o no ser, el acto concreto será de una manera o de otra a través de la aplicación de algún tipo de fuerza, no como resultado del despliegue inevitable de un proceso gobernado por una racionalidad trascendental. 
de (des)conexiones. Estas no vienen de la nada ni empiezan de cero, la novedad que incorporan es siempre una diferencia frente a un orden dado.

La novedad puede ser producida a partir de cualquier tipo de articulación a partir de conexiones anteriores. La agencia no es tanto una propiedad o un efecto de entidades ya prefijadas, sino precisamente condición y posibilidad de conexiones y relaciones. Si no fuera porque reproduce un tipo de mirada total de la que queremos escaparnos, diríamos que todo son relaciones, conexiones. Sin embargo, admitimos que estas conexiones se fijan constituyendo entidades como cuerpos, prácticas, agentes, objetos, etc. Todos ellos son parte de nuestras herramientas para tratar de delimitar esta efervescencia relacional y a la vez actores partícipes de las relaciones.

Así, «tener agencia» es estar en situación (relacional) de funcionar cuestionando-generando conexiones, a partir de otras conexiones. En este sentido la idea de agencia que aquí se propone se conecta con el concepto de deleuziano de agenciamiento:

Un agenciamiento es una multiplicidad que comporta muchos términos heterogéneos, y que establece uniones, relaciones entre ellos [...] La única unidad del agenciamiento es de co-funcionamiento: una simbiosis, una «simpatía». Lo importante no son las filiaciones, sino las alianzas y las aleaciones; ni tampoco las herencias o las descendencias, sino los contagios, las epidemias, el viento. (Deleuze y Parnet, 1997: 79)

Y este último concepto nos remite de nuevo a los contagios y defensas que conforman el concepto de Esposito de inmunitas. La agencia, como potencia, es capaz de ser un elemento conformador al tiempo que negación de la vida. Opera generando-subvirtiendo conexiones. Actuar es conectar, desconectar y reconectar; generar nuevos significados y nuevas posibilidades (incluso otras nuevas formas de agencia, otras subjetividades, otras estructuras, otras relaciones semióticas y materiales). Así, la propia producción de responsabilidad, la propia territorialización de la agencia, a través de un agenciamiento, es un proceso que genera conexiones, abre y cierra otros cursos de acción, otros posibles-imposibles. Por eso entendemos este proceso desde un punto de vista pragmático y semiótico, no ontológico. No se trata de desvelar una naturaleza, sino de producir efectos.

La pedagogía política ha de ser agencia para la conformación del hecho educativo como acto político que es. Y esto es así porque, frente a la división estructura sujeto, diremos que la agencia es anterior a la estructura y al sujeto, no participa de la ontología binaria que alimenta estos conceptos, descrita anteriormente. Sin embargo, tampoco va en contra de ellos. Estructura y sujeto pueden ser considerados como elementos dinamizadores de la agencia dentro de un determinado «juego del lenguaje». Pueden funcionar como operadores en el movimiento de territorialización de una potencia, pero no son, ni mucho menos, lo único que puede funcionar de esa manera. 
La pedagogía política ha de ser agencia educativa porque tampoco es la acción, es su condición de posibilidad, algo más básico y primario. En realidad, afinando algunos conceptos, la acción puede ser entendida como proceso y como flujo a partir del encadenamiento de actos. La acción es una forma de construir una cierta continuidad en la repetición de actos, pero son los actos, los acontecimientos, los que permiten hablar de acción. No existe como ente aislado.

La pedagogía política vista como agencia educativa nos va a remitir a la posibilidad de un acto político; es decir, a la producción de efectos de novedad en la tensión entre «lo posible» $\mathrm{y}$ «lo imposible»; a un acto que pretende instaurar una norma para la que no existe un fundamento último. En este sentido podemos entender la agencia como potencia. Hemos hablado de la potencia como la apertura de lo posible en la acción hacia una novedad imposible; como lo que muestra la contingencia del ser, a la vez que la necesidad de la existencia.

La pedagogía política como agencia y asumiendo el acto político anterior nos ofrece poder, nos empodera como movimiento hacia la regularidad y la repetición. Así, en el acto político se produce una «inversión» del poder. La potencia desborda al poder como condición de lo posible para proponer la instauración de lo imposible. Lógicamente, así como no puede haber novedad si no hay regularidad, no hay potencia sin poder $^{20}$.

Una agencia que no depende de la intención de los sujetos y es anterior a ellos. No es, por tanto, una propiedad-capacidad de los sujetos. Más aún, es una propiedad que emerge en las relaciones. La pedagogía política es una agencia que asume un rol mediador entre cursos de acción; señala y construye una posición intermediadora. La agencia como alternativa de fundamentación parcial, precaria y situada frente a la fundamentación necesaria que se proponía desde el sujeto puro y trascendental de la modernidad.

Además y como ya se ha comentado, la configuración de la pedagogía política como una agencia nos va a permitir construir un lugar de responsabilidad para la acción. Preguntarse por la agencia supone atribuir responsabilidades. Así, la agencia frente a los discursos que sitúan la noción de responsabilidad como una característica solo humana (no decimos que no haya responsabilidad humana) nos permite radicalizar la responsabilidad al politizarla, al vincularla a una posición en una trama de relaciones, no a una tarea predeterminada o a una naturaleza previa a contextos concretos. La responsabilidad implica dar cuenta del lugar de enunciación y reconocer que ese lugar puede estar habitado por muy diferentes voces, que es un lugar compartido o que deben ser escuchadas todas las influencias existentes.

${ }^{20} \quad$ La distinción (y tensión) entre poder y potencia es planteada por Antonio Negri a partir del pensamiento de Baruch Spinoza en La anomalía salvaje. Ensayo sobre poder y potencia. Allí se afirma: «Potencia como inherencia dinámica y constitutiva de lo singular y de la multiplicidad, de la inteligencia y del cuerpo, de la libertad y de la necesidad - potencia contra poder - allí donde el poder es un proyecto para subordinar a la multiplicidad, a la inteligencia, a la libertad, a la potencia» (Negri, 1993: 317). 
Lo que se ha querido proponer es que la pedagogía política debe conformarse de una manera que no vaya contra la política, más bien propone entender lo político de un modo no - plenamente- moderno, pero comprometido y situado con posiciones concretas que no son ni quieren ser neutrales. Como ya se ha presentado, la idea de responsabilidad como capacidad de actuar es central en esta perspectiva y marca con nitidez un punto de partida y una preocupación ético-política. El descentramiento del sujeto humano significa que no estamos solos ni solas; sin embargo, no podemos esperar que alguien lo haga por nosotros/as. Nuestra agencia educativa, y por lo tanto política, es nuestra capacidad de establecer vínculos, de articular, de participar junto con otras personas. De ser con otros seres humanos y de hacer-nos con ellos y ellas.

\section{Bibliografía}

Althusser, L.: Ideología y aparatos ideológicos del Estado. Freud y Lacan, Buenos Aires, Nueva Visión, 1988.

Antón VAlero, J. A. y Ros, A.: «La pedagogía crítica desde la perspectiva de los movimientos sociales», Tabanque, n. ${ }^{\circ}$ I7 (2003).

Ayuste, A.; Flecha, R.; López Palma, F. y Lleras, J.: Planteamiento de la pedagogía crítica. Comunicar y transformar, Barcelona, Graó, 1994.

Bourdieu, P.: Cuestiones de Sociología, Madrid, Istmo, 2000.

Bourdieu, P.: Lección sobre la lección, Barcelona, Anagrama, 2002.

Butler, J.: Mecanismos psíquicos del poder. Teorías sobre la sujeción, Madrid, Cátedra, $200 \mathrm{I}$.

CASAdo, E.: "A vueltas con el sujeto del feminismo», Política y Sociedad, 30 (1999).

Castells, M.: La era de la Información. Economía, sociedad y cultura, Madrid, Alianza, 1997.

Deleuze, G. y Guattari, F.: Mil mesetas. Capitalismo y esquizofrenia, Valencia, Pretextos, 2000.

Deleuze, G. y Parnet, C.: Diálogos, Valencia, Pretextos, 1997.

Ema López, J. E.: «Del sujeto a la agencia (a través de lo político)», Athenea Digital, 5 (2004). Disponible en http://analya.uab.es/athenea/nums/rema.pdf

Esposito, R.: Communitas. Origen y destino de la comunidad, Buenos Aires, Amorrortu, 2003.

Esposito, R.: Immunitas. Protección y negación de la vida, Buenos Aires, Amorrortu. 2005.

Foucault, M.: Historia de la Sexualidad. La voluntad de saber, México, Siglo XXI, 1997.

Freire, P.: Pedagogía del oprimido, Madrid, Siglo XXI, I970.

Freire, P.; Fiori, P. y Fiori, H.: Educación liberadora, Madrid, Ed. Zero, 1978.

Giddens, A.: La constitución de la sociedad. Bases para la teoría de la estructuración, Buenos Aires, Amorrortu, 1995.

Giddens, A.: La tercera vía. La renovación de la socialdemocracia, Madrid, Taurus, 1999.

Giroux, H.: Cultura, política y práctica educativa, Barcelona, Graó, 20oI.

Giroux, H.: «Educando para el futuro: rompiendo la influencia del neoliberalismo», Revista de Educación, núm. extraordinario (2002).

Haraway, D.: Ciencia, cyborgs y mujeres. La reinvención de la naturaleza, Madrid, Cátedra, 1995.

Hernández Díaz, J. M. ${ }^{a}$ : «Degradar la universidad o elevarla», Ensino Magazine, n. ${ }^{\circ} 205$ (marzo, 20I5).

Mcintyre, A.: «How psychology makes itself true or false», en Koch, S. y Leary, D. E. (eds.): A century of psychology as science, New York, McGraw-Hill, 1985.

Miller, G. A.: «Psychology as a means of promoting human welfare», American Psychologist, 24(I2) (1969). 
Negri, A.: La anomalía salvaje. Ensayo sobre poder y potencia en B. Spinoza, Barcelona, Antrophos, 1993.

PARDo, J. L.: «Las desventuras de la potencia (otras consideraciones inactuales)», LOGOS. Anales del Seminario de Metafísica, 35 (2002), pp. 55-78.

Skliar, C. y Téllez, M.: Conmover la educación. Ensayos para una pedagogía de la diferencia, Buenos Aires, Noveduc, 2008.

Touraine, A.: ¿Cómo salir del liberalismo?, Paidós. México, 1999. 